\title{
Brazilian scientist is part of elite group of researchers fighting cancer, obtains an unprecedented patent in the United States ${ }^{1}$
}

\author{
Katona, DL. ${ }^{a *}$, Vempati, $S .^{b}$ and Savir, OS. ${ }^{c}$ \\ a55 $5^{\mathrm{TH}}$ Ave, $18^{\mathrm{TH}} \mathrm{FL}$, New York, NY, 10003, USA \\ b809 2 $2^{\text {ND }}$ St. \#904, Union City, NJ, 07087, USA \\ `4 Morris Road, West Orange, NJ, 07052, USA \\ *e-mail: dkatona@nanocaretechnologies.com
}

Received: December 9, 2014 - Accepted: December 15, 2014 - Distributed: March 31, 2015

In 1966, researchers at Princeton University in the United States first isolated a family of vegetable stress hormones called Jasmonates, a family with several elements with structures similar to the human prostaglandin, that had stress-reducing properties. These hormones developed over millions of years as plants adapted to nature's threats including hydration stress or attacks by predators. Similar to animals, plants are faced with many of the same problems - a need for regulation of the metabolic process, healthy reproduction and for the defense against enemies. Jasmonates within plants serve a key role in the genes as well as in the metabolic regulation. They are also responsible for a plant's defense, the response for trauma, reproduction and possibly vital to their own communication (Liechti and Farmer, 2002). Plants' stress hormones are known as the key activators in cellular response, including cell death and diverse stress situations in plants.

Dr. Eliezer Flescher of Tel Aviv University theorized that the jasmonate cellular response function might be something to test for in human cells, more specifically cancer cells. Dr. Flescher through trial and error isolated a member of the Jasmonate family, the methyl jasmonate ("MJ"), as an agent that could have cancer-fighting capabilities. Dr. Flescher observed that the methyl jasmonate suppressed the proliferation of lymphoblastic leukemia cells and caused suppression of the cell proliferation in the other humans' cancer cells including prostate, breast and melanoma (Fingrut and Flescher, 2002).

Dr. Eliezer Flescher's studies concluded that methyl jasmonate, could induce direct perturbation of cancer cells mitochondria leading to release of the cytochrome $\mathrm{c}$ and eventual cell death. However, the most important characteristic of the methyl jasmonate was its ability to selective kill cancer cells while sparing normal cell activity. Dr Flescher's tests were performed within a mixed population of normal and leukemic cells derived from blood of chronic lymphocytic leukemia (CLL) patients. Methyl jasmonate killed preferentially only the leukemia cells (Flescher, 2005). Methyl jasmonate thus became an ideal candidate to initiate apoptosis, or programmed cell death in cancerous cells. At first, the explanation for the mechanism of action of the jasmonate killing the cancer

${ }^{1}$ In the memory of Eliezer Flescher cells stemmed back to the early 1920 s when the most striking biochemical phenotype of cancer, its aberrant energy metabolism, was discovered. Unlike normal tissue cells that derive much of their energy (ATP) by metabolizing sugar glucose into carbon dioxide and water in a process that involves oxygen-dependent organelles called mitochondria, studies performed by Otto Warburg showed that cancer cells frequently relied less on mitochondria by obtaining as much as $50 \%$ of their ATPs by metabolizing glucose directly into lactic acid, even in the presence of oxygen. This phenotype became known as the Warburg Effect (Pedersen, 2007).

Mitochondria in cancer cells generally have a malfunction of their selective permeability (Flescher, 2005). Most of the studies using jasmonates to treat cancer cells were taking advantage of a defect in the mitochondria in those cells, as the selective action of methyl jasmonate can safely be used to initiate apoptosis in defective cells while leaving healthy cells untouched. Flescher and his group found out three possible pathways to better describe how jasmonates selectively targeted cancer cells: 1 - the bio-energetic mechanism-jasmonate induced severe ATP depletion in cancer cells via mitochondrial perturbation, 2 - the re-differentiation mechanism-jasmonate induced re-differentiation in human myeloid leukemia cells via mitogen- activated protein kinase (MAPK) activity. 3- The reactive oxygen species (ROS)-mediated mechanism-jasmonate induced apoptosis in lung carcinoma cells via the generation of hydrogen peroxide, and pro-apoptotic protein of the Bcl-2 family. Many similarities between the effects of jasmonates on plants and cancer cells have been recorded, suggesting that additional analysis of jasmonate effects in plant cells may contribute to a deeper understanding of the anti-cancer actions of these compounds (Flescher, 2007).

Studies intensified as others international groups began researching plant stress hormones as promising approaches and possible therapies for cancer treatments. Many studies used pure methyl jasmonate or a similar cis-formulation of MJ as others elements from this plant hormone's family. The Methyl Jasmonate is a chemically fragile ester structure, it is not easily delivered to the cancerous cells, usually degrading before it reaches the tumor. Among all the various elements found in the Jasmonate family, 
one has shown to be much more effective towards the elimination of cancer cells, the methyl dihydrojasmonate, known as MDJ. Additional to the fragility of Jasmonate ester structure, the methyl dihydrojasmonate molecule, is an oily solution where there might be secondary problems once it reaches the blood stream. Dr. Flescher's research opened new avenues for cancer treatment but there nevertheless remained a serious obstacle, in how to bring jasmonate effectively inside of the cancer cell. Flescher, himself, theorized the addition of many other molecules, like sugar, into the methyl jasmonate formulation. Many of Dr. Flescher's experiments required enormous quantities of Methyl Jasmonate be administered in order for a very small portion to reach the intended target.

In 1998 independent of work being done in Israel, a Brazilian scientist, Dr. Jose Emilio Fehr Pereira Lopes began studying methyl jasmonate and in special the methyl dihydrojasmonate's potential effects in cancer cells. Dr. Lopes first studied fertilized eggs' natural defense activated by methyl jasmonate. Dr. Lopes approached his research from a different direction than Flescher and other groups, but with the same target to see cancer cells destroyed. From Dr. Lopes' studies, great leaps toward developing a functional cancer treatment were made. Dr. Pereira Lopes began observing the angiogenesis process into chicken embryos and their development as a phenomenon of an egg's natural defense against invading agents. In further tests, cancer cells were used in Dr. Lopes' experiments. He injected cancer cells inside of the chicken chorioallantoic membrane (CAM) in the second day of the eggs incubation. Due to the successful results in this protocol, many other humans cancer cells were injected into the egg's CAM expecting the formation of cancer cells colonies, tumors. For the first eggs injection in this protocol, Dr. Pereira Lopes first choice was the use of a murine melanoma cells (B16F10) due its facility and rapid growth abilities as well as the ability to observe these colonies without the need of a microscope once it can be seen the dark color produced by the cancer cells fast growing lawers at the chickens embryonic structure and the wide vessel network formed by this melanoma cells. After 10 days of incubation, the eggs are administered methyl jasmonate and methyl dihydrojasmonate in the same site where the cancers cells were originally injected eight days earlier. Dr. Fehr Pereira Lopes found that the melanomas colonies size were diminishing drastically due the interruption of blood distribution to the tumor and subconsequently the lack of delivery the vital nutrition to the tumors cells to survive and expand it. In order to better understand this vessels, created by the carcinogen phenomenon, disfunction, when jasmonates were injected, a parallel study was performed by Dr. Lopes to better comprehend this complexed process of the formation of new vessels by tumor in order to receive all the fundamental ingredients allowing it to grow named tumor's angiogenesis. The scientist, Dr. José Emilio Fehr Pereira Lopes, through a new experiment found out that in vitro, $1-10 \mathrm{mM}$ of methyl jasmonate and methyl dihydrojasmonate induced the cell death of the human umbilical vein endothelial cells (HUVEC) and the murine melanoma cells (B16F10) while the smaller concentrations were ineffective towards HUVECs, but effective towards the cancer cells (Pereira Lopes, 2009). Such results showed an effect into the new vessels that were built from the cancer colonies sparing the normal endothelial cells from vessels that were not originated from the cancer complex. In the cancer cells angiogenesis the MJ and the MDJ provoked an increase capillary budding, but the cancer originated vessels were leakier and less organized than the corresponding controls, showing an inefficient blood network that was incapable to perform the tumor nutrition and quickly led to cell death and following tumor disappearing. (Pereira Lopes et al., 2010).

Since 1990, angiogenesis has been one of the major focal points in cancer research. Credited to Dr. Judah Folkman whose published work titled, "What is the evidence that tumors are angiogenesis dependent?" (Folkman, 1990), cancer researchers have been looking for a way to stop cancerous blood vessels from forming and leading the tumor to starve it to death. In his research, Dr. Lopes discovered that the same mitochondrial defect and Warburg effect also exists in the endothelial cells used by the tumor to build new vessels during the angiogenesis process, indicating that these could also be killed using methyl jasmonate and it's derivative. The anti-angiogenesis effect discovered by Dr. Fehr Pereira Lopes' using plant stress hormone created a second effective weapon against cancer by preventing tumors from receiving the vital nutrients and oxygen as it requires to grow. Dr. Folkman had originally discovered the VEGF, a signal created by the tumor to develop its own vessels to receive the elements necessary to its expansion. This discovery was the hallmark of Dr. Folkman's research, paving the way for the development of many other molecules created to destroy tumors by starvation or anti-angiogenesis used nowadays.

Dr. José Emilio Fehr Pereira Lopes' studies on angiogenesis and its reverse effect, anti-angiogenesis, propelled him to the forefront of cancer research with a promise for the treatment of cancers directly related to this phenomenon, specifically melanoma and angiosarcoma. While studying the anti- angiogenisis effect in cancer, Dr. Pereira Lopes discovered additional cancer cell's signals that were blocked by the use of this plant stress hormone, furthering his research of a drug that acts on different fronts to destroy harmful cancer cells. These signals are myriad of other signals found, including some released during apoptosis that permitted trunk cells of the cancer to spread out and multiply, causing future metastases elsewhere in the body. During tests in eggs, Dr. Lopes faced many of the same obstacles other groups were having in their in-vivo tests in the use of jasmonates and it's derivative as a new agent to be used as an anti-cancer molecule, the degradation of the molecule by the body's metabolism. Dr. José Emilio Fehr Pereira Lopes' greatest world contribution to cancer research was the method he devised to turn jasmonates into a successful targeted cancer-killing 
agent. The great promising event for cancer treatment event happened years later when Dr. Fehr Pereira Lopes created a new molecule in 2008. Due this creation, the biggest obstacle found in the Jasmonate's delivery could finally be surmounted by coating this plant hormone in a specially designed sugar molecule inspired by a cyclodextrin. This newly formed compound was named A14. The A14 molecule complex functions much like a Trojan horse by using a carrier to reach the intended target. When A14 (a sugar carrier- jasmonate compound) enters a regular, healthy cell, it does not find the dysfunctional permeability of the pores of the mitochondria, and it is expelled providing zero toxicity or side effects. Given that a cells main source of energy is sugar, which is transformed into energy inside of a cell's mitochondria, all cells take in A14 where MJ/MDJ is then released. However, when A14 enters a cancerous cell that cell consumes the sugar coating, releasing the jasmonate elements and initiating apoptosis. Because the technique targets cells with the mitochondrial defect, it can target not only the tumor but also all the vessels formed through the VEFG signal. A14 goes even further, as it not only kills cancer cells, but also blocks cell signals that release trunk cells, thus preventing cancer from resurfacing, it became a promise to avoid metastasis' formation.

In 2012 Harvard University's Dana Farber Cancer Institute invited Dr. Lopes to test this new formulation in chemotherapy-cancer-resistant cells. In these experiments, Dr. Lopes used cell lines resistant to conventional chemotherapy and found that the replication processor of the colonies for tumor formation were successfully eliminated. Prior tests at the Butantan Institute of Sao Paulo, Brazil, showed confirmed the signaling process during apoptosis were blocked and there was a stimulation of the immune system with the subsequent growth of macrophages, which became effective against the growth of cancer cells.

A14 is the product of Dr. Fehr Pereira Lopes' years of hard work and dedication, but its development continues to be funded privately. In 2010, US based Nanocare Technologies, Inc. was formed to fund this research, launching Dr. Pereira Lopes into the global vanguard of cancer treatment. While a Brazilian patent is in the works, on November 11, 2014 the United States Patent Office issued a patent to Nanocare Technologies with Dr. Lopes listed as sole inventor. Dr. Lopes has also received an extraordinary abilities visa granted by the US Government for his leading work in cancer research.

\section{References}

FINGRUT, O. and FLESCHER, E., 2002. Plant stress hormones suppress the proliferation and induce apoptosis in human cancer cells. Leukemia, vol. 16, no. 4, p. 608-616. http://dx.doi.org/10.1038/ sj.leu.2402419. PMid:11960340

FLESCHER, E., 2005. Jasmonates: a new family of anti-cancer agents. Anti-Cancer Drugs, vol. 16, no. 9, p. 911-916. http:// dx.doi.org/10.1097/01.cad.0000176501.63680.80. PMid:16162967

FLESCHER, E., 2007. Jasmonates in cancer therapy. Cancer Letters, vol. 245, no. 1-2, p. 1-10. http://dx.doi.org/10.1016/j. canlet.2006.03.001. PMid:16600475

FOLKMAN, J., 1990. What is the evidence that tumors are angiogenesis dependent? Journal of the National Cancer Institute, vol. 82, no. 1, p. 4-6. http://dx.doi.org/10.1093/jnci/82.1.4. PMid: 1688381

LIECHTI, R. and FARMER, EE., 2002. The jasmonate pathway. Science, vol. 296, no. 5573, p. 1649-1650. http://dx.doi.org/10.1126/ science.1071547. PMid:12040182

PEDERSEN, PL., 2007. Warburg, me and Hexokinase 2: Multiple discoveries of key molecular events underlying one of cancers' most common phenotypes, the "Warburg Effect", i.e., elevated glycolysis in the presence of oxygen. Journal of Bioenergetics and Biomembranes, vol. 39, no. 3, p. 211-222. http://dx.doi. org/10.1007/s10863-007-9094-x. PMid:17879147

PEREIRA LOPES, JEF., 2009. Efeito antiangiogênico do metil jasmonato, puro ou nanocarreado, um novo mecanismo para sua ação antineoplásica e antimetastática. São Carlos: Universidade de São Paulo. Tese de Doutorado. Available from: $<$ http://www. teses.usp.br/teses/disponiveis/88/88131/tde-04092009-142533/ pt-br.php>.

PEREIRALOPES, JEF., BARBOSA, MR., STELLA, CN., SANTOS, WA., PEREIRA, EM., NOGUEIRA-NETO, J., AUGUSTO, EM., SILVA, LV., SMAILI, SS. and GOMES, LF., 2010. In vivo antiangiogenic effects further support the promise of the antineoplasic activity of methyl jasmonate. Revista Brasileira de Biologia = Brazilian Journal of Biology, vol. 70, no. 2, p. 443-449. http:// dx.doi.org/10.1590/S1519-69842010000200029. PMid:20549071 